Géopolitique de la connaissance et transferts culturels

\title{
Réponse à Fabian Heubel
}

\section{François JULLIEN}

\section{(2) OpenEdition \\ Journals}

Édition électronique

URL : http://journals.openedition.org/transtexts/567

DOI : $10.4000 /$ transtexts.567

ISSN : 2105-2549

Éditeur

Gregory B. Lee

Référence électronique

François JULLIEN, «Réponse à Fabian Heubel », Transtext(e)s Transcultures 跨文本跨文化 [En ligne],

9 | 2014, mis en ligne le 05 octobre 2015, consulté le 20 avril 2019. URL : http://

journals.openedition.org/transtexts/567 ; DOI : 10.4000/transtexts.567

Ce document a été généré automatiquement le 20 avril 2019.

(c) Tous droits réservés 


\title{
Réponse à Fabian Heubel
}

\author{
François JULLIEN
}

1 Il n'y a pas dia-logue entre Monsieur Fabian Heubel et moi-même.

2 Dans nos quelques rencontres, Fabian Heubel a, chaque fois, attaqué d'emblée mon travail sans commencer de m'écouter. Ce qui le conduit à une présentation caricaturale, étonnamment réductrice, de mes concepts, notamment d'écart et d'entre; ainsi que de ma stratégie philosophique, qui n'est pas du « comparatisme ». A-t-il commencé vraiment de me lire? Il est notamment dommage que Fabian Heubel n'ait pas ouvert celui de mes livres qui traite directement des questions qui le concernent ici: De l'universel, de l'uniforme, du commun et du dialogue entre les cultures, Fayard, 2008, pourtant largement accessible puisque traduit, entre autres langues, en allemand (Merve) et en anglais (Polity) et à paraître en chinois cette année (Presses de l'Université de Pékin).

3 Je me demande si l' «auto-blocage » qu'il décèle dans ma pensée ne serait pas la projection du sien.

4 Sur tous les points néanmoins intéressants abordés dans le texte de Fabian Heubel (métissage, modernité de la culture chinoise, transculturalité et mondialisation, etc.) et pour ouvrir effectivement le débat, je souhaiterais que le lecteur se reporte à la mise au point que j'ai faite dans la postface de mon dernier essai : De l'être au vivre, lexique eurochinois de la pensée, Gallimard, 2015, et dont le titre est lui-même significatif à cet écart : « De l'écart au commun ».

5 Ensuite, à chacun de bâtir sa propre réflexion.

6 François Jullien

7 Le 03/09/2015 